\title{
Australia reworks research philanthropy to fill unmet need
}

Australians are known to be good at cheering on their sports teams and incredibly generous in times of crisis, as reflected by the level of public giving after the 2004 Indian Ocean tsunami. Yet philanthropic funding for health and medical research is relatively low by international standards. Researchers now hope to improve this situation with the implementation of several new capacitybuilding initiatives.

"While more than half of Australians support medical research, the amounts given are less than one sixth of their total philanthropic contributions, and they are considerably lower per capita in comparison with the USA," says Rebecca James, chief executive of Research Australia, a non-profit alliance of around 180 members from the health and medical science community.

Scientists say private funding could help tremendously. The primary source of government funding for medical research is distributed on a competitive peer-reviewed basis via the National Health and Medical Research Council (NHMRC). Last year, only $23 \%$ of NHMRC applications were funded, yet an additional $58 \%$ of applications were deemed to be fundable but missed out (the most ever).

To help increase investment in and philanthropic support for health and medical studies, Research Australia established a dedicated charitable center called Research Australia Philanthropy (RAP). One of RAP's aims is to address barriers to giving to medical research, such as the difficulty for donors in locating relevant research groups and organizations and evaluating the quality of their science.

Last September, RAP brought out a 'tool kit', which is essentially a folder of information and resources for individuals, foundations, companies, professional advisers and researchers hoping to attract philanthropic support. It ties in with RAP's linkage program, launched a few months earlier, that is based on the use of a new online research register-called the Philanthropy Registerwhich helps RAP to match potential donors with scientists.

Access to the register is limited to RAP. Grant makers pay matchmaking fees, but they are commensurate with the size of the grant and the needs of the grant giver, as the process involves varying levels of due diligence and can require RAP to set up a research-review or peer-review committee.

The RAP Philanthropy Register follows on from the RAP's successful 2008 pilot program that linked State Trustees Australia Fund with researchers. It resulted in them supporting three projects to the total tune of AU\$55,000 $(\$ 47,000)$.

"Researchers can spend up to $25 \%$ of their time writing grants instead of doing research; we hope to reduce duplication of effort and ensure that there's concordance between the grant maker and grant seeker before time is invested in the writing of a full application," explains Noel Chambers, director of RAP.

One of the additional ways RAP hopes to make it easier for scientists is by partnering with funding bodies to share information. "In the case of Cancer Australia [a government agency], they send through electronic information about grants that have missed out in the funding rounds. We'd like to form similar arrangements with other trusts and companies," he says.

\section{Unknown effects}

To date, RAP's initiatives have resulted in a few matches between scientists and philanthropists. But large-scale success lies in the hands of the researchers seeking philanthropic funds; only hundreds out of thousands of potential projects have been registered. Bob Graham, president of the Association of Australian Medical Research Institutes (AAMRI), a membership body that represents the majority of the country's major medical research institutes, which are themselves Research Australia members, says that although they have passed on information about this innovative initiative to all of their members, more awareness is needed, and that it is still too soon to judge how the initiative will be received by the Australian public.

The online registration is designed to take 20 minutes and includes a question on the type of support required; the options are capital works, equipment, a research project or a clinical trial.

Some people worry, however, that funders might shy from costs related to infrastructure. "The problem is that funding indirect costs is

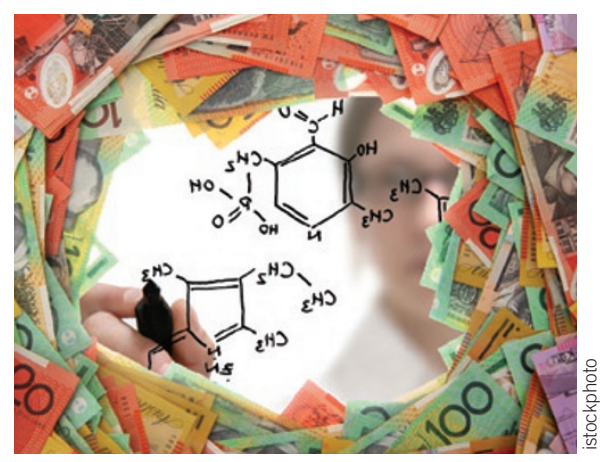

In the hole: Philanthropies plug the funding gap.

not an attractive proposition to most donors," says Peter Schofield, executive director of Neuroscience Research Australia, a Sydneybased institute. "Really, what we should be saying is that the true cost of research is the true cost of research-business costs are certainly not separated in this way."

Indeed, the scientific community has been working hard to get government to acknowledge and address the need for covering full research costs. A January L.E.K. Consulting report called Costing Medical Research to Reform Health Outcomes, commissioned by AAMRI, calculated indirect costs to be, on average, an additional 60 Australian cents for every dollar of successfully attained competitive grant funding. In most Australian states, half of the indirect costs are met by state and federal government funds, leaving a shortfall of $20 \%$ of the full research cost.

By 2014, a new plan will help fund indirect costs of research conducted by universities, but medical research institutes are not eligible for these funds and, additionally, will no longer qualify for partial payment of indirect costs that arise from collaborations with universities.

Moreover, not all research grants will qualify. "Charitable foundations and trusts like the National Heart Foundation, the Cancer Council and overseas funding agencies, including NIH [the US National Institutes of Health] and the Wellcome Trust, do not provide for the full costs of the research, so that gap still has to be met from other sources," says Graham.

"There needs to be a paradigm shift in the way we view and provide research funding," Schofield adds. "It's difficult to ask donors and charities to meet the full costs of the research if government doesn't."

Branwen Morgan, Sydney 